\title{
Aplikasi Seven Tools untuk Mengurangi Cacat Produk White Body pada Mesin Roller
}

Tio Prima Matondang, M. Mujiya Ulkhaq*

Departemen Teknik Industri, Universitas Diponegoro, Jl. Prof. Soedarto, SH., Tembalang, Semarang 50275, Indonesia

\section{ARTICLE INFORMATION}

Article history:

Received: July 25, 2017

Revised: August 25, 2018

Accepted: September 03, 2018

Kata Kunci:

Pengendalian Kualitas

Seven Tools

Statistika Pengendalian Kualitas

Keywords:

Quality Control

Seven Tools

Statistical Process Control

*Corresponding Author

M. Mujiya Ulkhaq

E-mail: ulkhaq@live.undip.ac.id

\section{A B S T R A K}

Penelitian ini bertujuan untuk menunjukkan aplikasi efektif dari metode seven tools sebagai salah satu dari quality management tools untuk mengurangi cacat pada produk. Studi kasus dilaksanakan pada proses produksi white body di PT. XYZ yang berlokasi di Semarang. Persentase cacat sangat tinggi dianggap sebagai salah satu penyebab tidak tercapainya target perusahaan. Seven tools yang mencakup check sheet, stratifikasi, histogram, scatter diagram, peta kendali, Diagram Pareto, dan diagram sebab-akibat digunakan untuk menganalisis penyebab terjadinya cacat. Berdasarkan hasil pengolahan data, didapatkan delapan jenis cacat, yaitu: tobi, hage, bakar ulang, crolling, saya boro, rusak back stamp, hama kake, dan nama kire. Rekomendasi usulan perbaikan telah diberikan dengan menggunakan analisis $5 \mathrm{~W}+1 \mathrm{H}$ untuk memperbaiki kinerja pengendalian kualitas perusahaan serta meminimalisasi produk yang cacat.

\section{A B S T R A C T}

This study aims to demonstrate effectively application of the seven tools as one of the quality management tools to reduce product defects. A case study has been conducted in the production of white body at PT. XYZ, which is located in Semarang. The high percentage of defects is considered as one causes of not attaining the target of the company. Seven tools, which consist of check sheet, stratification, histogram, scatter diagram, control chart, Pareto chart, and cause-and-effect diagram, are used to analyze the causes of the defects. Based on data processing results, there are eight types of defects, namely: tobi, hage, burn back, crolling, saya boro, broken back stamp, hama kake, and nama kire. Recommendations for improvement have been proposed using $5 \mathrm{~W}+1 \mathrm{H}$ analysis to improve the company's quality control performance and minimize product defects.

\section{PENDAHULUAN}

Perusahaan manufaktur dewasa ini mengalami perkembangan yang sangat pesat akibat dampak dari globalisasi. Ditambah dengan maraknya perdagangan bebas yang memungkinkan barang impor dari luar negeri dapat dipasarkan di dalam negeri dengan harga yang tidak jauh berbeda dengan barang lokal. Semakin meningkatnya persaingan di pasar global, membuat perusahaan manufaktur yang ingin memenangkan persaingan dituntut untuk mampu menghasilkan produk terbaik dengan kualitas yang tinggi [1].

Kualitas merupakan salah satu parameter dalam persaingan industri [2]. Hal ini mengakibatkan perusahaan perlu melakukan analisis dan perbaikan untuk menjaga agar kualitas produk yang dihasilkan sesuai dengan keinginan konsumen. Alternatif yang dapat dilakukan oleh perusahaan adalah dengan melakukan pengendalian kualitas dari produk yang dihasilkan. Pengendalian kualitas bertujuan untuk menekan jumlah produk yang cacat serta menjaga agar produk akhir sesuai dengan spesifikasi dan standar yang telah ditetapkan oleh perusahaan [3].

PT. XYZ merupakan perusahaan manufaktur yang memproduksi produk keramik jenis peralatan rumah tangga dan saniter. Hasil produksinya didistribusikan baik di pasar lokal Indonesia (dengan target produksi 20\%) maupun untuk 
pasar global atau ekspor (dengan target $80 \%$ ). Dalam upayanya mengendalikan kualitas, PT. XYZ mempunyai Divisi Total Quality Control yang bertugas memonitor kualitas produk yang dihasilkan sejak kedatangan bahan baku hingga produk akhir sampai pada proses pengepakan.

Pada praktiknya, PT. XYZ belum mampu untuk mencapai target $80 \%$ dari produknya untuk diekspor ke pasar luar negeri. Dari penelitian pendahuluan yang telah dilakukan ditemukan salah satu penyebabnya adalah banyaknya produk cacat yang ditemukan pada mesin roller.

Untuk memperbaiki kondisi tersebut, diperlukan adanya analisis mengenai penyimpangan yang terjadi didalam proses produksi serta mencari penyebab cacat produk yang ditimbulkan. Selain itu, dibutuhkan pula strategi perbaikan sebagai upaya untuk meminimalisasi cacat produk sehingga cacat produk tidak terulang kembali.

Dalam penelitian ini, digunakan metode seven tools (yang merupakan kajian dalam statistical process control) untuk mengatasi permasalahan yang ada. Metode ini sudah banyak diterapkan untuk mengatasi permasalahan serupa pada berbagai perusahaan, baik manufaktur maupun jasa. Aplikasi metode seven tools digunakan untuk mengurangi cacat produk pada Mesin Communite di PT. Masscom Graphy, Semarang [4]. aplikasi seven tools untuk menganalisis penyebab cacat produk galon di PT. Berlina, Tbk., Surabaya [5]. dan implementasi seven tools untuk meningkatan kualitas produk pada mesin produksi nonwoven spunbond [6]. Pada penelitian ini, selain metode seven tools yang digunakan untuk menganalisis penyebab cacat, digunakan pula metode $5 \mathrm{~W}+1 \mathrm{H}$ untuk memberikan rekomendasi perbaikan dengan mengidentifikasi penyebab penyimpangan kualitas produk yang terjadi.

\section{METODE PENELITIAN}

Kualitas didefinisikan sebagai keseluruhan fitur dan karateristik dari barang dan jasa yang mampu memenuhi kebutuhan yang terlihat atau yang tersamar [7], [8]. Kualitas merupakan kata kunci dalam semua persaingan industri, sehingga setiap perusahaan harus bisa menghasilkan suatu produk dengan kualitas yang baik dan memenuhi kebutuhan konsumen [9]. Sedangkan pengendalian kualitas merupakan kegiatan pengawasan yang dilakukan oleh setiap komponen dalam perusahaan untuk meningkatkan dan mempertahankan produksinya agar produk yang dihasilkan sesuai dengan standar kualitas produk yang diharapkan dan sebagai usaha untuk mengarahkan agar kesalahan kualitas tersebut tidak terjadi dalam proses produksi, sehingga usaha untuk memenuhi standar kualitas dapat tercapai [10].

Penelitian ini akan menggunakan salah satu metode dalam pengendalian kualitas yang termasuk kedalam statistika pengendalian kualitas, yaitu metode seven tools. Seven tools terdiri dari:

a. Check sheet atau lembar pemeriksaan merupakan lembar pengumpulan data yang digunakan untuk memudahkan dan menyederhanakan pencatatan data. Tujuannya adalah untuk menjamin bahwa data dikumpulkan secara teliti dan akurat oleh karyawan operasional untuk diadakan pengendalian proses dan penyelesaian masalah. Lembar pemeriksaan bisa digunakan untuk mengetahui distribusi proses produksi, mengetahui jumlah produk yang cacat, lokasi cacat, dan sebab kecacatan.

b. Stratifikasi merupakan tabel yang mengklasifikasikan permasalahan (dalam hal ini kecacatan) kedalam beberapa kelompok. Penelitian ini mengelompokkan produk yang cacat kedalam jenis-jenis kecacatannya.

c. Histogram adalah semacam diagram batang yang digunakan untuk menunjukkan variasi suatu data. Dalam konteks manajemen kualitas, histogram adalah perangkat grafis yang menunjukkan distribusi, sebaran, dan bentuk pola data dari suatu proses [11]. Jika data yang terkumpul menunjukkan bahwa proses tersebut stabil dan dapat diprediksi, kemudian histogram dapat digunakan untuk menunjukkan kemampuan proses. Meski sekelompok data memiliki standar kualitas yang sama, tetapi bila penyebaran data semakin melebar ke kiri atau ke kanan, maka dapat dikatakan bahwa kualitas hasil produksi pada kelompok tersebut kurang, sebaliknya, semakin sempit sebaran data pada kiri dan kanan nilai tengah, maka hasil produksi dapat dikatakan lebih berkualitas, karena mendekati spesifikasi yang telah ditetapkan.

d. Scatter diagram (diagram pencar) digunakan untuk menyatakan korelasi atau hubungan antara satu faktor dengan karakteristik yang lain atau sebab dan akibat [12]. Jika kedua variabel tersebut berkorelasi, titik-titik koordinat akan jatuh di sepanjang garis atau kurva. Semakin baik korelasi, semakin ketat titik-titik tersebut mendekati garis.

e. Control chart (peta kendali) adalah peta yang digunakan untuk perubahan proses dari waktu ke waktu. Melalui gambaran tersebut akan dapat dideteksi apakah proses tersebut ber 
Tabel 1. Contoh check sheet hasil produksi pada mesin roller untuk produk white body (dalam satuan unit produk)

\begin{tabular}{ccccrc}
\hline Tanggal & Total Kenza & E/B1 & RF & \multicolumn{1}{c}{ B2 } & Loss \\
\hline $05 / 06-11 / 06$ & 114.463 & 88.595 & 14.493 & 9.316 & 2.059 \\
$12 / 06-18 / 06$ & 115.541 & 87.617 & 14.516 & 10.566 & 2.842 \\
$19 / 06-25 / 06$ & 114.543 & 88.665 & 14.717 & 9.284 & 1.877 \\
$26 / 06-02 / 07$ & 115.796 & 88.149 & 14.377 & 10.117 & 3.153 \\
$03 / 07-09 / 07$ & 115.733 & 87.891 & 14.268 & 10.683 & 2.891 \\
$10 / 07-16 / 07$ & $112 . .303$ & 84.849 & 14.690 & 9.613 & 3.151 \\
$17 / 07-23 / 07$ & 116.735 & 88.133 & 14.543 & 10.931 & 3.128 \\
$24 / 07-30 / 07$ & 110.561 & 84.668 & 14.446 & 8.965 & 2.842 \\
\hline
\end{tabular}

jalan baik (stabil) atau tidak [13], [14]. Peta tersebut digunakan untuk mengevaluasi apakah suatu proses berada dalam pengendalian kualitas secara statistik atau tidak. Karakteristik pokok peta kendali adalah adanya sepasang batas kendali (upper dan lower limits), sehingga dari data yang dikumpulkan akan dapat terdeteksi kecenderungan kondisi proses yang sesungguhnya.

f. Diagram Pareto adalah bagan yang berisikan diagram batang dan diagram garis. Diagram batang memperlihatkan klasifikasi dan nilai data, sedangkan diagram garis mewakili total data kumulatif. Klasifikasi data diurutkan dari kiri ke kanan menurut urutan ranking tertinggi hingga terendah. Ranking tertinggi merupakan masalah prioritas atau masalah yang terpenting untuk segera diselesaikan, sedangkan ranking terendah merupakan masalah yang tidak harus segera diselesaikan. Prinsip diagram Pareto sesuai dengan hukum Pareto yang menyatakan bahwa sebuah grup selalu memiliki persentase terkecil $(20 \%)$ yang bernilai atau memiliki dampak terbesar $(80 \%)$ [15], [16]. Diagram Pareto mengidentifikasi $20 \%$ penyebab masalah vital untuk mewujudkan $80 \%$ perbaikan secara keseluruhan.

g. Diagram sebab-akibat atau sering disebut fishbone diagram (diagram tulang ikan) adalah alat untuk mengidentifikasi berbagai sebab potensial dari satu efek atau masalah dan menganalisis masalah tersebut melalui sesi brainstorming [17]. Masalah akan dipecah menjadi sejumlah kategori yang berkaitan; mencakup manusia, material, mesin, prosedur, kebijakan, dan sebagainya. Setiap kategori mempunyai sebab-sebab yang perlu diuraikan melalui sesi brainstorming [18].

Data yang digunakan dalam penelitian ini berupa data sekunder, yakni berupa data produksi dan jumlah cacat produk selama setengah tahun terakhir, yaitu bulan Juni sampai Desember.
Penelitian ini bersifat penelitian deskriptif analisis yaitu penelitian yang memaparkan pemecahan masalah terhadap suatu masalah yang ada secara sistematis dan faktual berdasarkan datadata yang ada. Penelitian ini meliputi proses pengumpulan, penyajian, pengolahan data, serta analisis, dan interpretasi. Metode pengolahan data yang dipakai untuk mengatasi masalah adalah menggunakan metode statistik, yaitu dengan seven tools.

\section{HASIL DAN PEMBAHASAN}

Berikut akan dijelaskan aplikasi metode seven tools untuk pengolahan data serta analisis penyebab-penyebab terjadinya kecacatan produk white body pada mesin roller di Departemen Produksi PT. XYZ.

\section{Check Sheet}

Pemeriksaan cacat produk dengan menggunakan check sheet bertujuan untuk memberikan informasi berupa data cacat produk yang berisi waktu pengamatan, jenis cacat, dan jumlah cacat. Contoh check sheet data cacat produk yang dicatat oleh operator untuk bulan Juni dan Juli diperlihatkan pada Tabel 1. Pada penelitian ini, hanya data RF yang akan dianalisis lebih lanjut.

\section{Stratifikasi}

Dari data jenis dan jumlah cacat pada produk cacat yang ada, maka dapat dilakukan pengklasifikasian data menjadi kelompok sejenis yang lebih kecil sehingga terlihat lebih jelas. Stratifikasi ini didasarkan pada delapan jenis cacat, yaitu:

a. Tobi (pinhole): Cacat tobi atau pinhole adalah jenis cacat berupa lubang jarum yang terdapat pada permukaan dan menembus lapisan white body.

b. Hage (knocking): Cacat hage merupakan jenis cacat pada body glaze karena terjadi benturan dengan benda lain.

c. Bakar Ulang (BU): Cacat BU berupa lapisan 
Tabel 2. Stratifikasi untuk RF

\begin{tabular}{lcc}
\hline Jenis cacat & $\begin{array}{c}\text { Jumlah cacat } \\
\text { (unit) }\end{array}$ & $\begin{array}{c}\text { Persentase } \\
(\%)\end{array}$ \\
\hline Tobi & 127.736 & $29,43 \%$ \\
Hage & 69.883 & $16,10 \%$ \\
BU & 5.873 & $1,35 \%$ \\
Crolling & 60.673 & $13,98 \%$ \\
SB & 137.730 & $31,74 \%$ \\
BST & 15.571 & $3,59 \%$ \\
HMKA & 16.349 & $3,77 \%$ \\
NKI & 150 & $0,03 \%$ \\
Total & 433.965 & $100,00 \%$ \\
\hline
\end{tabular}

glaze pada white body yang belum merata dan berdampak pada permukaan yang kasar. Crolling: Cacat crolling merupakan jenis cacat berupa lapisan glaze yang lepas dari body pada saat pembakaran seperti tobi tetapi lebih besar atau lebar.

d. Saya Boro (SB): Cacat SB merupakan jenis cacat pada body yang terdapat kotoran dari refractory.

e. Rusak Back Stamp (BST): Jenis cacat BST berupa cap atau stamp pada belakang white body yang rusak.

f. Hama Kake (HMKA): Cacat HMKA terdapat pada kaki body yang gumpil.

g. Nama Kire (NKI): Cacat NKI berupa retak pada body yang terjadi sebelum dibakar.

Stratifikasi untuk data cacat produk white body diperlihatkan pada Tabel 2.

\section{Histogram}

Histogram menunjukkan jumlah kecacatan yang dibagi ke dalam jenis-jenis kecacatan. Sumbu- $x$ menunjukkan kelas yang terbentuk dari masingmasing jenis cacat, sedangkan sumbu-y memperlihatkan frekuensi dari setiap kelas tersebut. Dengan menggunakan Software SPSS versi 23, Gambar 1 menampilkan histogram dari kedelapan jenis cacat. Terlihat bahwa tidak semua jenis cacat mengikuti distribusi normal. Hal ini menunjukkan frekuensi terjadinya kecacatan tidak memusat pada rata-ratanya, atau bisa dikatakan lebih bervariasi.

\section{Scatter Diagram}

Scatter diagram menggambarkan korelasi atau hubungan dari suatu penyebab terhadap faktor lain atau terhadap akibat atau karakteristik lain. Dengan menggunakan scatter diagram akan terlihat kedekatan dari dua data. Pada penelitian ini, dua data yang dicari kedekatan hubungannya yaitu antara jenis kecacatan yang satu dengan lainnya. Contoh scatter diagram untuk cacat Tobi dengan lainnya digambarkan pada Gambar 2.

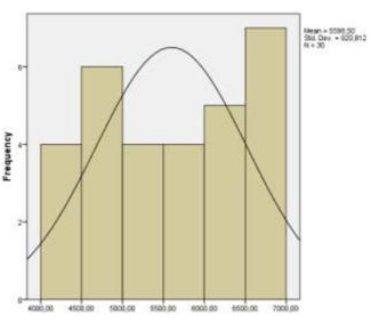

(a) Tobi

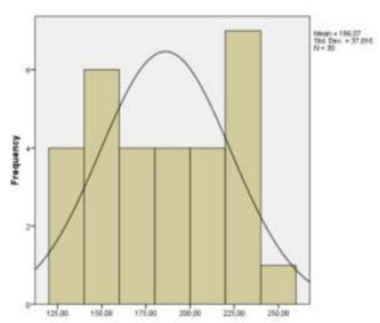

(c) BU

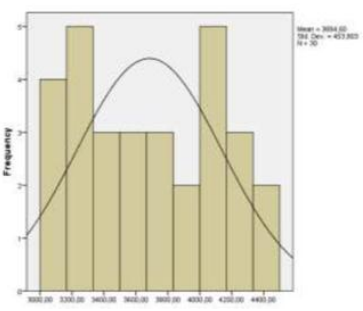

(e) SB

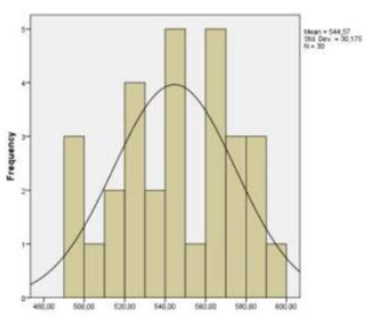

(g) HMKA

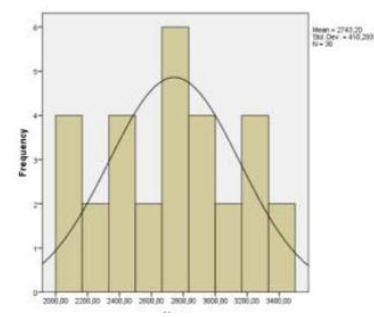

(b) Hage

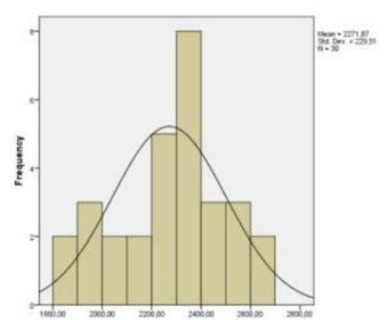

(d) Crolling

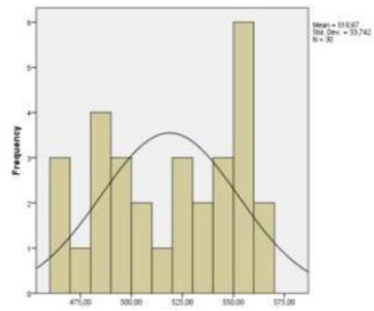

(f) BST

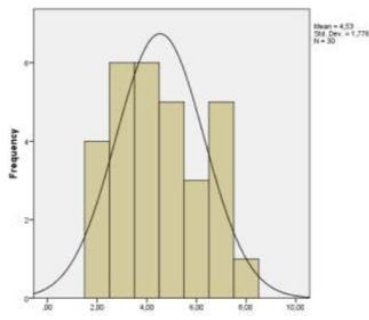

(h) NKI
Gambar 1. Histogram jenis cacat

Dari ketujuh scatter diagram yang ada, terlihat bahwa tidak ada kecenderungan cacat Tobi berkorelasi terhadap jenis cacat yang lain, artinya cacat yang terjadi independen.

\section{Control Chart}

Control chart adalah suatu peta yang digunakan untuk mengevaluasi suatu proses, apakah dalam keadaan terkendali secara statistik atau tidak. Dalam penelitian kali ini, peta kendali yang digunakan adalah peta kendali $p$ (proporsi kecacatan). Peta kendali ini digunakan untuk mengetahui apakah cacat produk yang dihasilkan masih dalam batas yang disyaratkan atau tidak. Peta kendali untuk tiap jenis kecacatan digambarkan pada Gambar 3. 


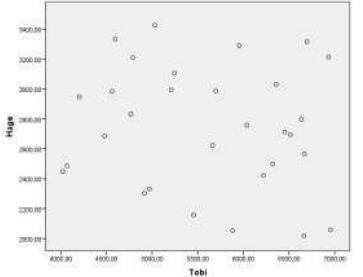

(a) Tobi vs. Hage

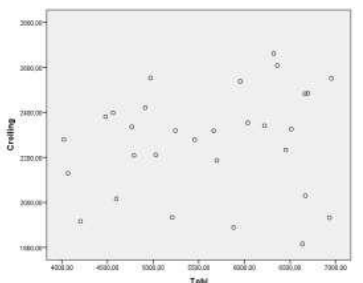

(c) Tobi vs. Crolling

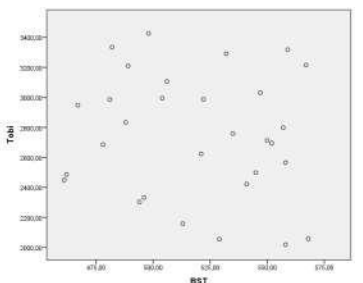

(e) Tobi vs. BST

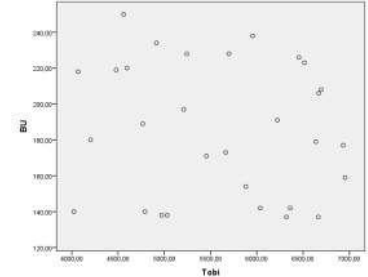

(b) Tobi vs. BU

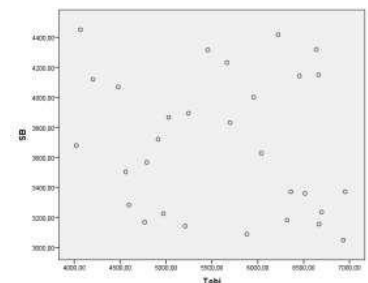

(d) Tobi vs. SB

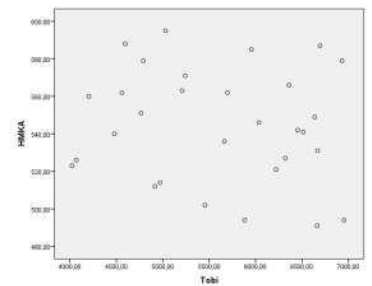

(f) Tobi vs. HMKA

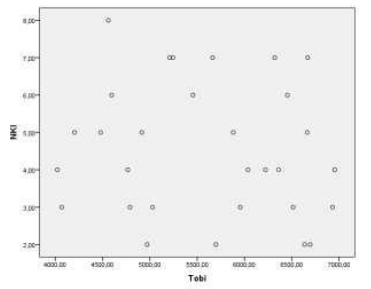

(g) Tobi vs. NKI

Gambar 2. Scatter diagram jenis cacat Tobi vs. jenis cacat lainnya

Gambar 3, memperlihatkan bahwa semua data proses berada dalam kondisi statistical in-control, sehingga batas kontrol yang didapatkan selanjutnya dapat digunakan untuk memonitor proses selanjutnya.

\section{Diagram Pareto}

Tujuan dari Diagram Pareto (gambar 4.) adalah untuk meranking jenis kecacatan yang paling tinggi (atau yang paling besar) dari beberapa jenis kecacatan yang ada.

\section{Diagram Sebab-Akibat}

Diagram sebab-akibat atau fishbone diagram digunakan untuk menganalisis penyebabpenyebab dari masalah yang terjadi berdasarkan

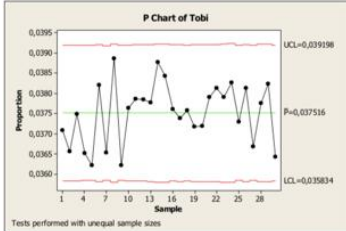

(a) Tobi

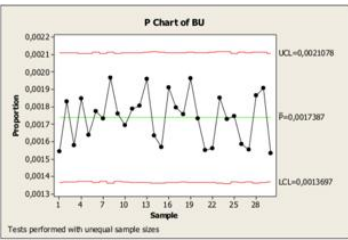

(c) BU

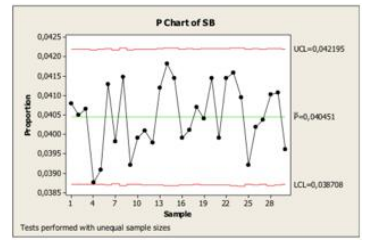

(e) SB

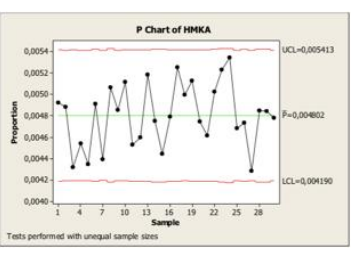

(g) HMKA

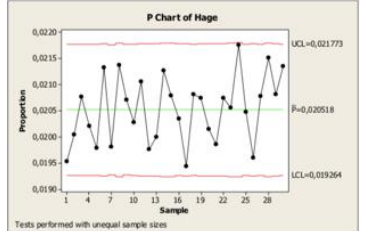

(b) Hage

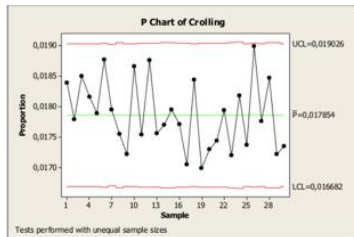

(d) Crolling

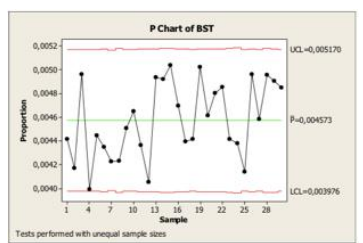

(f) BST

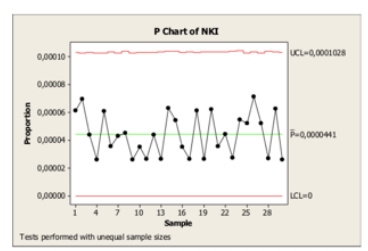

(h) NKI
Gambar 3. Control chart jenis cacat

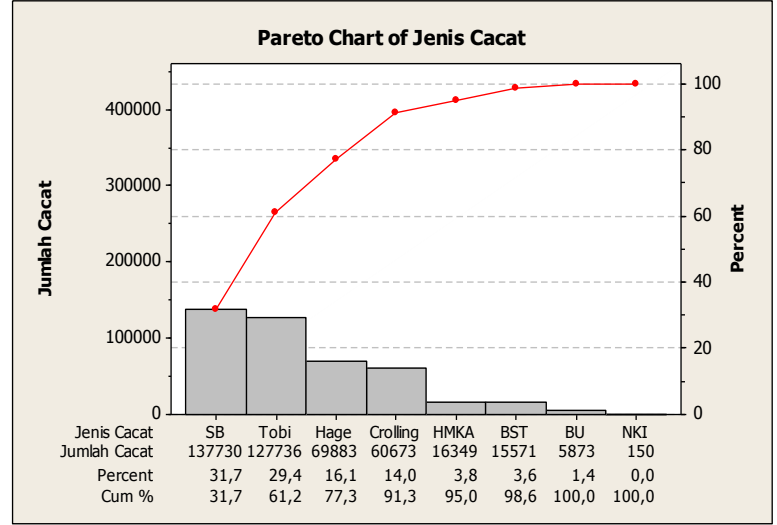

Gambar 4. Diagram Pareto

hasil yang diperoleh dari Diagram Pareto, diketahui bahwa masalah yang paling butuh perhatian khusus adalah cacat NKI karena cacat paling sedikit justru akan menimbulkan masalah yang besar; sehingga akan dianalisis penyebab- 


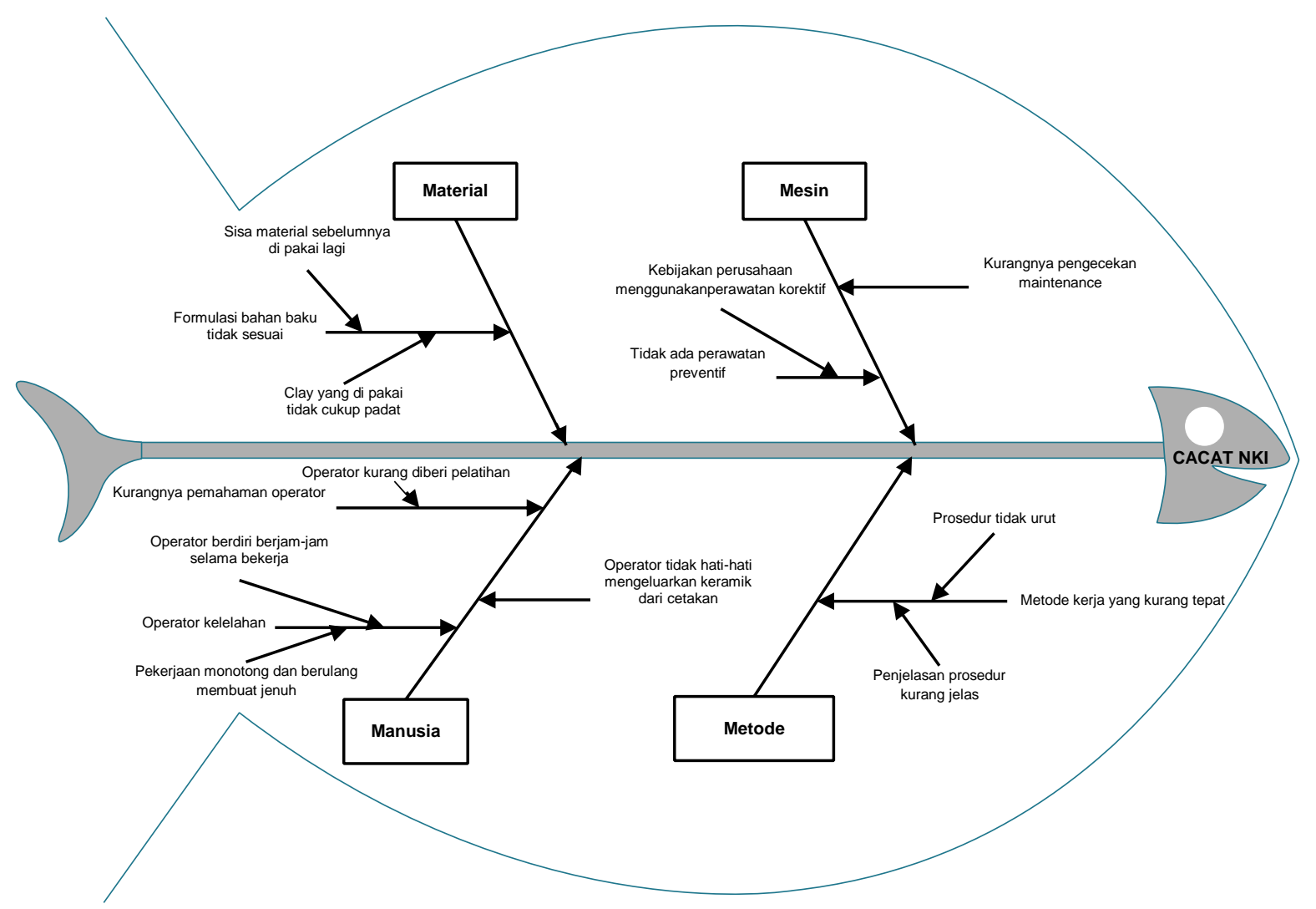

Gambar 5. Diagram sebab-akibat

penyebab cacat NKI dengan empat faktor utama yaitu material, metode, manusia, dan mesin. Diagram sebab-akibat ditunjukkan pada Gambar 5.

a. Faktor material: cacat NKI terjadi karena formulasi bahan baku yang tidak sesuai. Faktor tersebut dapat terjadi karena terdapat impurities pada bahan baku dan clay yang digunakan tidak cukup padat. Hal ini bisa dikarenakan operator inspeksi kurang teliti pada saat melakukan inspeksi bahan baku dan kurang memperhatikan prosedur mengenai komposisi bahan baku.

a. Faktor machine/mesin: cacat NKI terjadi karena tidak ada perawatan preventif terhadap mesin roller karena perusahaan menggunakan kebijakan perawatan korektif. Faktor tidak ada perawatan preventif terjadi karena belum ada prosedur yang mengatur perawatan mesin secara preventif. Faktor lain adalah kurangnya pengecekan perawatan terhadap mesin.

b. Faktor man/manusia: cacat NKI terjadi karena kurangnya pemahaman operator sepenuhnya terhadap mesin roller. Faktor yang menyebabkan hal ini adalah karena kurangnya pelatihan pada para pekerja. Faktor lain adalah kurangnya kehati-hatian operator saat mengeluarkan produk dari cetakan yang bisa disebabkan karena kurangnya pemahaman tentang prosedur kerja. Faktor lain adalah karena operator kelelahan yang diakibatkan karena pekerjaan yang berulang dan monoton selama berjam-jam dan pekerja yang diharuskan berdiri untuk menangani mesin.

c. Faktor method/metode: cacat NKI terjadi karena metode kerja yang kurang tepat, misalnya kurangnya ketelitian operator dalam menyentuh keramik yang belum kering dan menggunakan material yang tidak sesuai.

\section{Saran Perbaikan}

Setelah dilakukan identifikasi penyebab cacat NKI pada produk whitebody, berikut adalah usulan perbaikan untuk mengurangi cacat tersebut dengan menggunakan metode $5 \mathrm{~W}+1 \mathrm{H}$, yang diperlihatkan pada Tabel 3. 
Tabel 3. Saran perbaikan dengan $5 \mathrm{~W}+1 \mathrm{H}$

\begin{tabular}{|c|c|c|c|c|c|c|}
\hline Faktor & What & Why & Where & When & Who & How \\
\hline $\begin{array}{l}\text { Formulasi } \\
\text { bahan } \\
\text { baku tidak } \\
\text { sesuai }\end{array}$ & $\begin{array}{l}\text { Melakukan } \\
\text { inspeksi } \\
\text { bahan } \\
\text { baku } \\
\text { dengan } \\
\text { lebih ketat }\end{array}$ & $\begin{array}{l}\text { Agar bahan } \\
\text { baku yang } \\
\text { digunakan } \\
\text { untuk } \\
\text { proses } \\
\text { produksi } \\
\text { memenuhi } \\
\text { standar }\end{array}$ & $\begin{array}{l}\text { Area raw } \\
\text { material }\end{array}$ & $\begin{array}{l}\text { Selama } \\
\text { proses } \\
\text { inspeksi } \\
\text { bahan baku }\end{array}$ & $\begin{array}{l}\text { Operator } \\
\text { inspeksi raw } \\
\text { material }\end{array}$ & $\begin{array}{l}\text { Melakukan } \\
\text { briefing } \\
\text { supaya } \\
\text { operator lebih } \\
\text { bertanggung } \\
\text { jawab }\end{array}$ \\
\hline $\begin{array}{l}\text { Tidak ada } \\
\text { perawatan } \\
\text { preventif }\end{array}$ & $\begin{array}{l}\text { Membuat } \\
\text { kebijakan } \\
\text { preventif }\end{array}$ & $\begin{array}{l}\text { Supaya } \\
\text { tidak terjadi } \\
\text { breakdown } \\
\text { tib-tiba }\end{array}$ & $\begin{array}{l}\text { Lantai } \\
\text { produksi } \\
\text { area } \\
\text { mesin } \\
\text { roller }\end{array}$ & $\begin{array}{l}\text { Menyesuai- } \\
\text { kan waktu } \\
\text { sebelum } \\
\text { produksi, jeda } \\
\text { produksi, dan } \\
\text { pasca } \\
\text { produksi }\end{array}$ & $\begin{array}{l}\text { Departemen } \\
\text { mainte- } \\
\text { nance }\end{array}$ & $\begin{array}{l}\text { Melakukan } \\
\text { perawatan } \\
\text { dan } \\
\text { pengecekan } \\
\text { mesin secara } \\
\text { rutin dan } \\
\text { terjadwal }\end{array}$ \\
\hline $\begin{array}{l}\text { Kurangnya } \\
\text { pemaham } \\
\text { operator } \\
\text { tentang } \\
\text { mesin } \\
\text { roller }\end{array}$ & $\begin{array}{l}\text { Memberi } \\
\text { pelatihan } \\
\text { pada } \\
\text { operator } \\
\text { mengenai } \\
\text { proses } \\
\text { operasi } \\
\text { dengan } \\
\text { mesin } \\
\text { roller }\end{array}$ & $\begin{array}{l}\text { Supaya } \\
\text { operator } \\
\text { bisa } \\
\text { mengopera- } \\
\text { sikan mesin } \\
\text { yang } \\
\text { menjadi } \\
\text { tanggung } \\
\text { jawabnya } \\
\text { dengan baik }\end{array}$ & $\begin{array}{l}\text { Lantai } \\
\text { produksi } \\
\text { area } \\
\text { mesin } \\
\text { roller }\end{array}$ & $\begin{array}{l}\text { Menyesuai- } \\
\text { kan waktu } \\
\text { pelatihan }\end{array}$ & $\begin{array}{l}\text { Operator } \\
\text { mesin roller }\end{array}$ & $\begin{array}{l}\text { Membuat } \\
\text { program } \\
\text { pelatihan } \\
\text { yang lebih } \\
\text { baik kepada } \\
\text { operator } \\
\text { supaya bisa } \\
\text { mengopera- } \\
\text { sikan mesin } \\
\text { dengan baik }\end{array}$ \\
\hline $\begin{array}{l}\text { Operator } \\
\text { kelelahan }\end{array}$ & $\begin{array}{l}\text { Memberi } \\
\text { fasilitas } \\
\text { yang lebih } \\
\text { ergonomis } \\
\text { untuk } \\
\text { pekerja }\end{array}$ & $\begin{array}{l}\text { Supaya } \\
\text { operator } \\
\text { tidak terlalu } \\
\text { cepat } \\
\text { kelelahan } \\
\text { akibat posisi } \\
\text { kerja yang } \\
\text { melelahkan }\end{array}$ & $\begin{array}{l}\text { Lantai } \\
\text { produksi } \\
\text { area } \\
\text { mesin } \\
\text { roller }\end{array}$ & $\begin{array}{l}\text { Menyesuai- } \\
\text { kan waktu } \\
\text { sebelum } \\
\text { produksi, jeda } \\
\text { produksi, dan } \\
\text { pasca } \\
\text { produksi }\end{array}$ & $\begin{array}{l}\text { Pengawas } \\
\text { lantai } \\
\text { produksi }\end{array}$ & $\begin{array}{l}\text { Penyediaan } \\
\text { fasilitas yang } \\
\text { lebih baik } \\
\text { untuk } \\
\text { operator }\end{array}$ \\
\hline $\begin{array}{l}\text { Operator } \\
\text { yang } \\
\text { kurang } \\
\text { memper- } \\
\text { hatikan } \\
\text { prosedur } \\
\text { kerja }\end{array}$ & $\begin{array}{l}\text { Memberi } \\
\text { peringatan } \\
\text { supaya } \\
\text { operator } \\
\text { bekerja } \\
\text { dengan } \\
\text { memperha- } \\
\text { tikan } \\
\text { standar } \\
\text { operasi- } \\
\text { onal }\end{array}$ & $\begin{array}{l}\text { Supaya } \\
\text { hasil } \\
\text { produksi } \\
\text { memenuhi } \\
\text { standar } \\
\text { produk dan } \\
\text { mencapai } \\
\text { target } \\
\text { produksi }\end{array}$ & $\begin{array}{l}\text { Lantai } \\
\text { produksi } \\
\text { area } \\
\text { mesin } \\
\text { roller }\end{array}$ & $\begin{array}{l}\text { Selama } \\
\text { proses } \\
\text { produksi } \\
\text { dengan mesin } \\
\text { roller }\end{array}$ & $\begin{array}{l}\text { Operator } \\
\text { mesin roller }\end{array}$ & $\begin{array}{l}\text { Melakukan } \\
\text { briefing dan } \\
\text { untuk } \\
\text { operator agar } \\
\text { lebih } \\
\text { bertanggung } \\
\text { jawab dalam } \\
\text { tugasnya }\end{array}$ \\
\hline $\begin{array}{l}\text { Metode } \\
\text { kerja } \\
\text { kurang } \\
\text { tepat }\end{array}$ & $\begin{array}{l}\text { Memberi } \\
\text { pelatihan } \\
\text { pada } \\
\text { operator } \\
\text { mesin } \\
\text { roller }\end{array}$ & $\begin{array}{l}\text { Supaya } \\
\text { pengerjaan } \\
\text { keramik } \\
\text { dilakukan } \\
\text { dengan } \\
\text { prosedur } \\
\text { dan sesuai } \\
\text { urutan yang } \\
\text { tepat }\end{array}$ & $\begin{array}{l}\text { Lantai } \\
\text { produksi } \\
\text { area } \\
\text { mesin } \\
\text { roller }\end{array}$ & $\begin{array}{l}\text { Menyesuai- } \\
\text { kan waktu } \\
\text { pelatihan }\end{array}$ & $\begin{array}{l}\text { Operator } \\
\text { mesin roller }\end{array}$ & $\begin{array}{l}\text { Membuat } \\
\text { program } \\
\text { pelatihan } \\
\text { yang lebih } \\
\text { baik kepada } \\
\text { operator }\end{array}$ \\
\hline
\end{tabular}




\section{KESIMPULAN}

Kesimpulan yang dapat diambil dalam penelitian ini adalah cacat produk yang dominan pada proses produksi white body adalah cacat SB yaitu sebesar $31,74 \%$ dan yang paling kecil adalah cacat NKI sebesar $0,03 \%$. Namun cacat $\mathrm{NKI}$ dianggap paling berkontribusi untuk kerusakan produk white body karena meski frekuensinya sedikit tetapi paling fatal kerusakannya. Penyebab cacat untuk cacat NKI dianalisis dengan mencari penyebab dari empat faktor: material, mesin, manusia, dan metode. Faktor material yang digunakan terdapat formulasi yang tidak sesuai standar; faktor mesin tidak dilakukannya perawatan secara rutin dan menggunakan kebijakan korektif untuk kerusakan; faktor manusia misalnya operator kurang paham terhadap mesin roller, operator yang kelelahan, dan operator yang kurang berhati-hati; faktor metode, kurangnya ketelitian operator dalam menyentuh keramik yang belum kering dan menggunakan material yang tidak sesuai. Usulan perbaikan telah direkomendasikan dengan menggunakan metode $5 \mathrm{~W}+1 \mathrm{H}$ dengan mempertimbangkan penyebab terjadinya cacat NKI meliputi apa yang harus dilakukan, mengapa hal tersebut perlu dilakukan, dimana, kapan, siapa yang terlibat, dan bagaimana pelaksanaannya.

\section{NOMENKLATUR}

Kenza $=$ Inspeksi Produk

$E / B 1$ = Produk dengan Kualitas yang Baik dan Tidak Cacat; yang akan Diekspor ke Luar Negeri $R F=$ Produk Cacat yang Harus Dikerjakan Ulang B2 = Produk yang Memiliki Sedikit Cacat tetapi Tidak Harus Dikerjakan Ulang dan Masih Bisa Dijual di Pasar Lokal

Loss = Produk Cacat yang Tidak Bisa Diperbaiki dengan Pembakaran Ulang dan Tidak Layak Dijual sehingga Akan Dibanting

\section{DAFTAR PUSTAKA}

[1] R. D. Banker, I. Khosla, and K. K. Sinha, "Quality and competition," Manage. Sci., vol. 44, no. 9, pp. 1179-1192, 1998.

[2] D. Hassan and S. Monier-Dilhan, "National brands and store brands: competition through public quality labels," Agribus. an Int. J., vol. 22, no. 1, pp. 2130, 2006.

[3] T. Conti, Building total quality: A guide for management. Springer Science \& Business Media, 2012.

[4] M. M. Ulkhaq, S. N. W. Pramono, and Rifki Halim, "Aplikasi seven tools untuk mengurangi cacat produk pada Mesin Communite di PT. Masscom Graphy, Semarang," J. PASTI, vol. 11, no. 3, pp. 220-230, 2017.

[5] M. M. Ulkhaq and D. R. Rasyida, "Aplikasi Seven Tools dan Analisis $5 \mathrm{w}+1 \mathrm{~h}$ untuk Mengurangi Cacat Produk Galon: Studi Kasus di PT. Berlina, Tbk," Pros. Semin. Nas. Multi Disiplin IImu Call Pap. UNISBANK Ke-2, pp. 330-338, 2016.

[6] M. Damaindra and A. S. Cahyana, "Peningkatan kualitas produk pada mesin produksi Nonwoven Spunbond dengan menggunakan metode seven tools dan FMEA," Spektrum Ind., vol. 15, no. 2, pp. 245-255, 2017.

[7] J. H. Heizer and B. Render, Operation Management, 10th edition. Upper Saddle River, NJ: Prentice Hall, 2011.

[8] J. E. Ross, Total quality management: Text, cases, and readings. Routledge, 2017.

[9] D. H. Besterfield, Total Quality Management, 3rd edition. New York: Pearson Education, Inc., 2003.

[10] A. Mitra, Fundamentals of quality control and improvement. New York: Springer Publishing Company, 2016.

[11] V. M. Magar and V. B. Shinde, "Application of 7 quality control $(7 \mathrm{QC})$ tools for continuous improvement of manufacturing processes," Int. J. Eng. Res. Gen. Sci., vol. 2, no. 4, pp. 364-371, 2014.

[12] J. J. Gunther and F. Hawkins, Making TQM work: Quality tools for human service organizations. Springer Publishing Company, 1999.

[13] P. Qiu, Introduction to statistical process control. Chapman and Hall/CRC, 2013.

[14] D. C. Montgomery and G. C. Runger, Applied statistics and probability for engineers. River Street, Hoboken: John Wiley \& Sons, 2010.

[15] D. L. Goetsch and S. B. Davis, Quality management for organizational excellence. Upper Saddle River, NJ: Pearson, 2014.

[16] J. J. Dahlgaard, G. K. Khanji, and K. Kristensen, Fundamentals of total quality management. Routledge, 2008.

[17] G. Ilie and C. N. Ciocoiu, "Application of fishbone diagram to determine the risk of an event with multiple causes," Manag. Res. Pract., vol. 2, no. 1, pp. 1-20, 2010.

[18] N. R. Tague, The quality toolbox, vol. 600. ASQ Quality Press Milwaukee, WI, 2005. 